\title{
Epoxy Composites Reinforced with Bazaltfibre Filled for Osteo-, Paleo-Prostheses and External Implants
}

\author{
Starokadomsky $\mathrm{D}^{1}$, Reshetnyk $\mathrm{M}^{2}$, Ishenko $\mathrm{A}^{3}$ and Rassohin $\mathrm{D}^{3}$ \\ ${ }^{1}$ Chuiko Institute of Surface Chemistry NAN, Composite Department, Ukraine \\ ${ }^{2}$ National Nature Historical Museum NAN, Geological/Paleontological Department, Ukraine \\ ${ }^{3}$ Pryazovsky State Technical University, Department of Mechanical equipment for metallurgy plants, Ukraine \\ *Corresponding author: Starokadomsky D, Chuiko Institute of Surface Chemistry NAN, Composite Department, Ukranine
}

\section{ARTICLE INFO}

Received: 慧 May 07, 2019

Published: 幽 May 15, 2019

Citation: Starokadomsky D, Reshetnyk M, Ishenko A, Rassohin D. Epoxy Composites Reinforced with Bazaltfibre Filled for Osteo-, Paleo-Prostheses and External Implants. Biomed J Sci \& Tech Res 18(1)-2019. BJSTR. MS.ID.003092.

\section{ABSTRACT}

The possibility of producing composites with 15-80 wt\% micronano Basalt Fiber (BF), characterized by several enhanced strength characteristics and higher chemical and fire resistance, was experimentally shown. It is shown that at medium concentrations (15 cpm\%) the properties of the composite slightly differ from the unfilled polymer (H-polymer). However, at $50 \mathrm{wt} \%$ and especially $80 \mathrm{wt} \%$, serious changes in properties are observed, reflecting a profound change in morphology. BasaltFibre (BF), SEM 50wt\% EpoxyBF Swelling in 1:1 acetone: ethylacetate for neat Epoxy (H1, H2) and 15-80 wt\% epoxyBF.

Keywords: Basalt Fibre Rein Forced Polymer (BFRP); Compression Strength; Tensile; Adhesion; Aqua-Endured Composites; Swelling; Resistance

\section{Introduction}

Epoxy composites are used in prosthetics and implantation [1-2]. In review [1], epoxy composites are referred with PMMA, PLA, and XEMA as composites for biomaterials (mainly for external prosthetics). Micronanobazalt fibers are seen as a tempting material for the technologically simple reinforcement of epoxy, polyester, and other thermo-reactive cross-linking polymers. Ideally, fibers of this size should give a mechanically strong interlocking with a polymer, and they can be expected to have considerable promise for practice. In addition, basalt, like other inorganic and oxide materials (glass \& silica [3], granite [4], aluminosilicates [5], gypsum or cement [6]), has excellent affinity for epoxides and other polar resins (Figure 1).

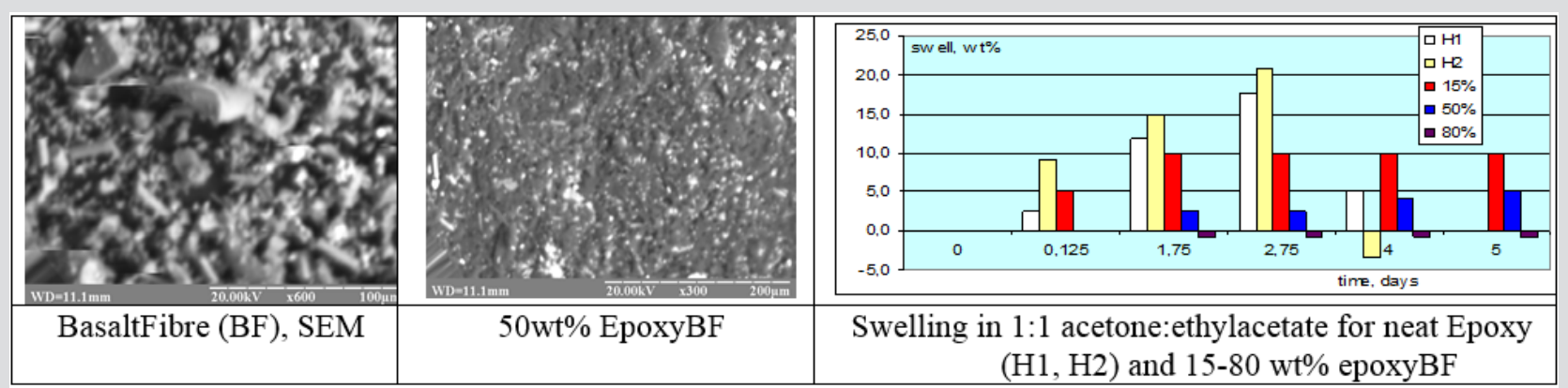

Figure 1: Swelling in 1:1 acetone: ethylacetate for neat Epoxy $(\mathrm{H} 1, \mathrm{H} 2)$ and $15-80 \mathrm{wt} \%$ epoxy BF.

Epoxy-basalt plastics are stronger and more durable than glass-plastics, and much cheaper than carbon and aramide [5]. Moreover, according to the latest data [8] they have not been studied as thoroughly as carbon and glass plastics. Now BFRP are using as a rule in build constructions $[9,10]$ and as thermally stable materials with high stiffness [11]. Over time, two branches of these 
works were defined - composites with continuous fiber [7-11], and composites with micro-nanofiber $[12,13]$. The use of BFRP is so wide now, that a problem of his utilization become actual [14]. Lapena+Marinucci [7] indicate the high resistance of epoxy basalts to alcohol environments. Epoxy-basalt plastics are stronger and more durable than glass-plastics, and much cheaper than carbon and aramid plastics. The properties of basalt and fiberglass are sometimes similar - for example, DSC curves and glass transition temperature [7]. The authors found that basalt plastic have a higher modulus of elasticity and flexural strength than similar fiberglass. Moreover, according to the latest data (Wu etc. [8]) they have not been studied as thoroughly as carbon and glass plastics. Now BFRP are using as a rule in build constructions [7] and as thermally stable materials with high stiffness [8].

According Shen etc. [15] a laminates reinforced with basalt fibers and functionalized multi-walled carbon nanotubes (MWCNTs) were fabricated from unidirectional epoxy prepregs was investigated. Niaki etc. [10] was found that increasing the amount of epoxy resin to the basalt aggregates to $25 \mathrm{wt} \%$ improved mechanical properties of the polymer concrete. The larger aggregate size outcomes higher compressive strength and lower flexural and splitting tensile strength. Bulut [12] showed that even miserable concentrations of BV (for example, $0.1 \mathrm{wt} \%$ ) can significantly improve the properties of epoxide, which is traditionally explained by a good interfacial interaction. Ulegin etc [13] showed that with an increase in the concentration of basalt cleansing (their size was within 140 microns), the degree of cure increases from 84 to $94 \%$, and at $90^{\circ} \mathrm{C}$ from 98.7 to $99.7 \%$.

Optical microscopic photo compositions are presented, from which a uniform distribution of basalt particles is seen. However, the temperature of degradation with filling almost does not change (from 200 to $210 \mathrm{C}$ ), although the oxygen index increases from 19-26 without filling to 37 . Wu et al. [11] concluded that epoxybasalt composites have not been studied as thoroughly as carbon and glass grades, which suggests the high relevance of such studies.

\section{Methods and Reagents}

Samples were prepared based on classic dianepoxy resin (Epoxy520) and PEPA hardener (5:1), with 10\% dilution with ethyl alcohol. The curing of the compositions was carried out by mixing these components with microno Basalt Fiber (BF).Compression tests (GOST 4651-68, USSR testing standart) were subjected to samples in the form of a cylinder with a diameter of $6.5 \mathrm{~mm}$ and a height of 10-12 mm (on a "LouisShopper" press machine) manufactured at $25^{\circ} \mathrm{C}$ and heat-treated. Tests on the adhesion gap (GOST 14760-69) were subjected to gluing metal cylinders with a diameter of $2.2 \mathrm{~cm}$ on the test binder "UMM-10 Armavir" (Figure 2).

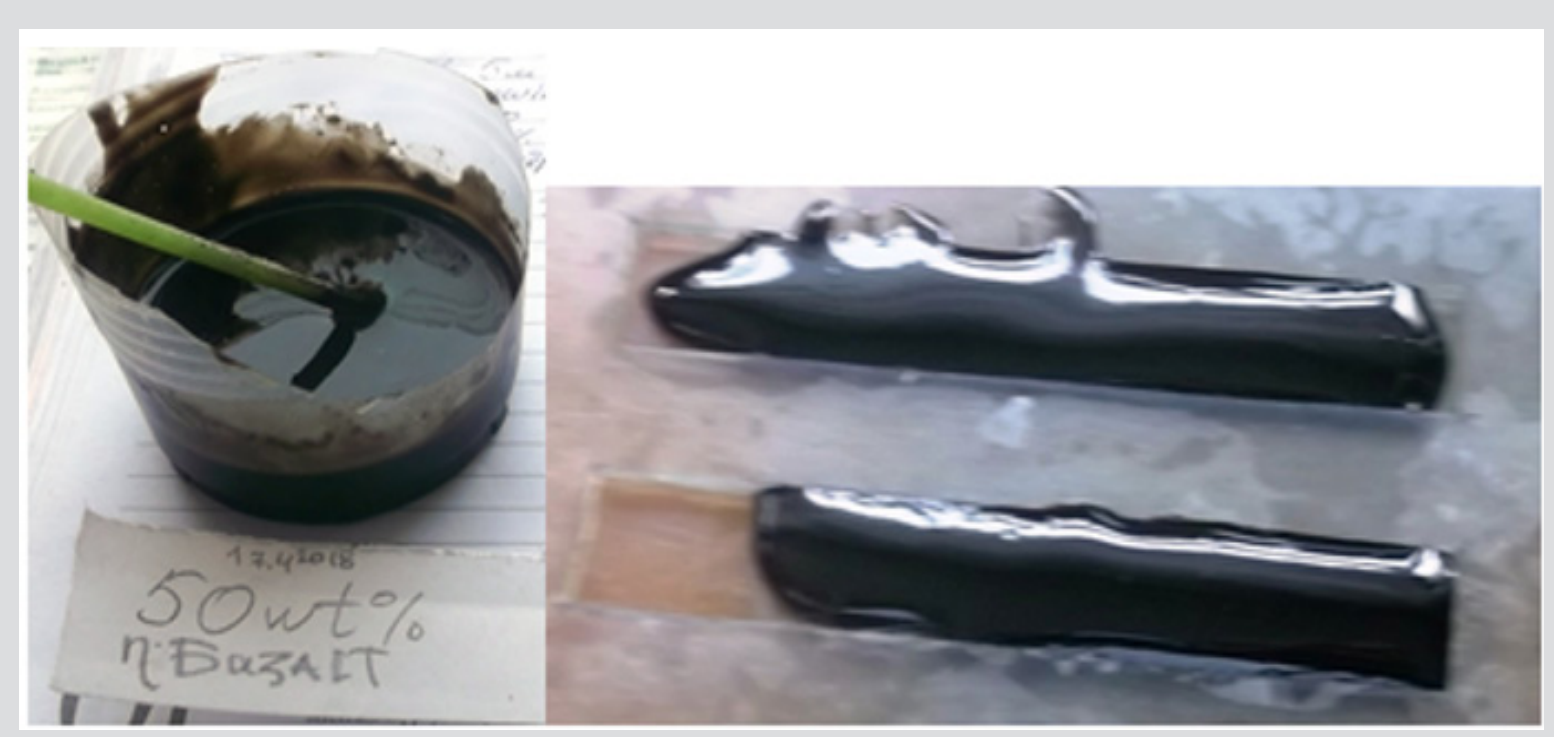

Figure 2: Visual aspect of tested compositions (50 wt \%), before hardening.

Tests on adhesion shear (GOST 14760-59) glued fiberglass plates with an area of $3 \mathrm{~cm}^{2}$ gluing were carried out on a ZIP-DI-1 unit. Bending tests (GOST) were subjected to samples of $12 \times 60 \times 2$ $\mathrm{mm}$ on a $40 \mathrm{~mm}$ base. The abrasion of the composites was measured by changing the mass of the sample after wiping the sample with P180 emery paper, 100 times cycling with a cycling path diameter of $5 \mathrm{~cm}$. Abrasion resistance was calculated using my empirical formula $\mathrm{T}=\rho \backslash(\rho \mathrm{OX})$ - where $\rho \backslash \rho \mathrm{o}$ is the ratio of densities of filled and unfilled polymers, $\mathrm{X}$ is the amount of abrasion. Fire resistance was measured as time (sec) of inflammation after contact with open fire. For swell testing, tablets $1 * 1 * 0.2 \mathrm{~mm}$ were placed in a mixture of acetone: ethyl acetate or $35 \%$ hydrogen peroxide. Weight change was recorded gravimetrically in wt\%. In Figure 3 (a neat dry BF, without epoxyresin) can see a several microtubes of BF. And in epoxypolymer a comparative homohenous dispercion of $\mathrm{BF}$ is seen (Figure 3). 

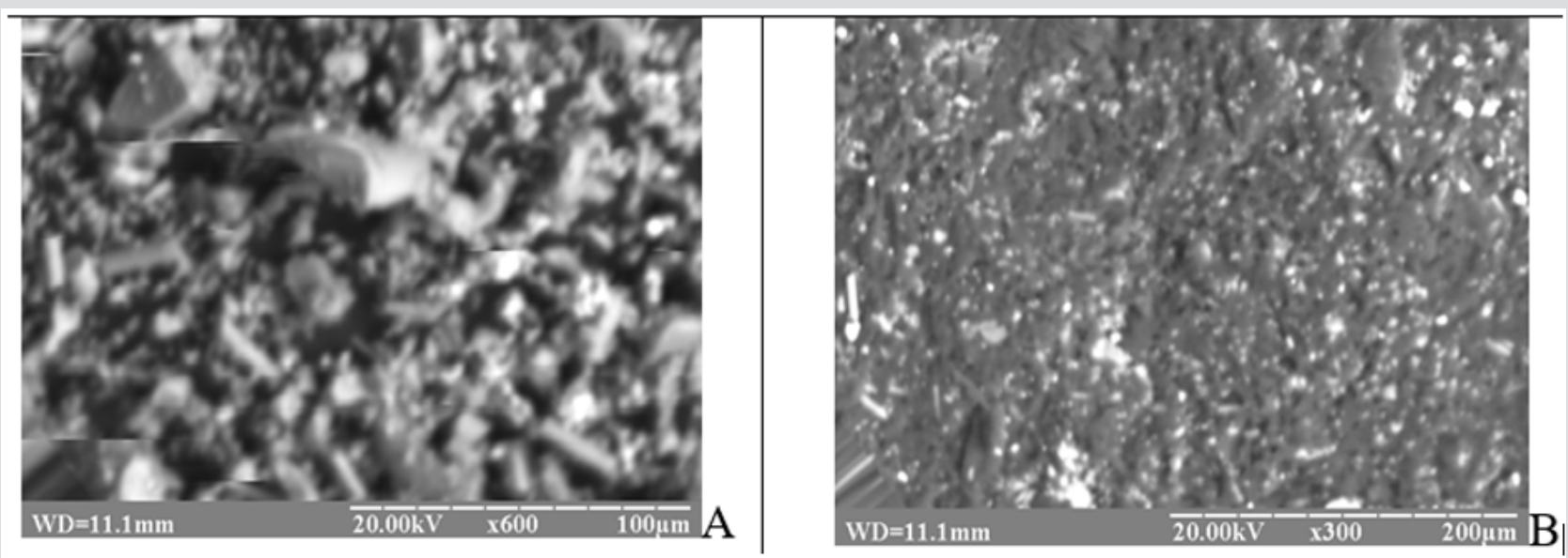

Figure 3: SEM-images of BF (A) and his $50 \mathrm{wt} \%$ epoxy-composites.

\section{Experimental Results}

\section{Strength and Thermostability}

Thermograms show that with increasing filling, there is a slight shift in the extremes of thermal destruction (see DTA and DTG curves in Figure 4) towards lower temperatures. Thus, the introduction of nano-basalt does not give the expected growth of heat resistance, and even vice versa. From Table 1 the introduction of microbasalt can increase compressive strength up to $10 \%$ (with measurement errors less than 5\%). The growth of the modulus of elasticity becomes noticeable even with a slight filling (15 Ams\%), with higher filling there is a further increase in the module. It is characteristic that a simple introduction of basalto roving into the resin does not give such an effect (Table 1).

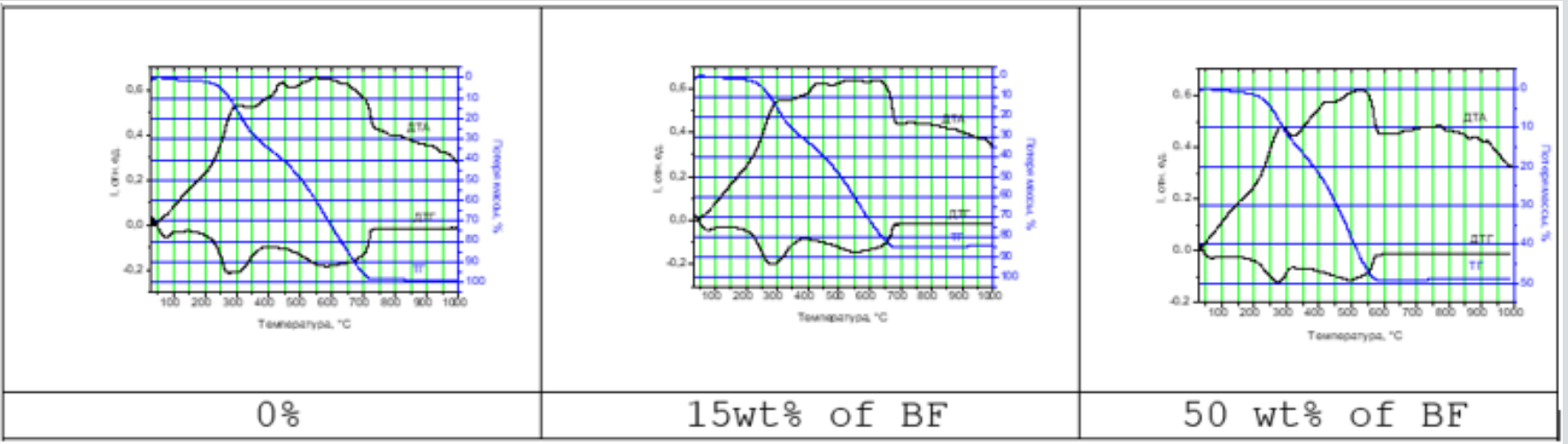

Figure 4: Thermogravimetric curves.

Table 1: Strength parameters of composites with micro basalt fiber. In index - load of final destruction.

\begin{tabular}{|c|c|c|c|c|}
\hline $\mathrm{N}_{1}$ & $\begin{array}{c}\text { Compression C, load (kgf) on cylinder } 7,5^{*} 12^{+-} \\
1 \mathrm{~mm}\end{array}$ & Modulus $* 10^{3} \mathrm{EC} \mathrm{kgf} / \mathrm{cm}^{2}$ & Tensile strength, $\mathbf{k g} \backslash \mathbf{c m}^{2}$ & Modulus E $10^{3 *} \mathrm{~kg} \backslash \mathrm{mm}^{2}$ \\
\hline H $(0 \%)$ & $450(100 \%)$ & 10,5 & 11.2 & 12,7 \\
\hline $15 \%$ & $490(109 \%)$ & 11.6 & 5.5 & 11,7 \\
\hline $50 \%$ & $440(98 \%)$ & 12,5 & 5.1 & 25 \\
\hline $80 \%$ & $495(110 \%)$ & 12 & 6.4 & 20 \\
\hline $\mathrm{N}_{2}$ & \multicolumn{3}{|c|}{ Comparative tests for epoxy + glass $\backslash$ basalt roving } & \\
\hline H $(0 \%)$ & $410(100 \%)$ & 9,5 & & \\
\hline Basalt & $420(102 \%)$ & 9 & & \\
\hline Glass & $380(93 \%)$ & 11,5 & & \\
\hline $\mathrm{N}_{3}$ & \multicolumn{2}{|c|}{ After immersion in $\mathrm{H}_{2} \mathrm{O}, 7$ days } & & \\
\hline
\end{tabular}




\begin{tabular}{|c|c|c|c|c|}
\hline $\mathrm{H}(0 \%)$ & $410(100 \%)$ & 10 & & \\
\hline $15 \%$ & $470(115 \%)$ & 10,3 & & \\
\hline $50 \%$ & $450(110 \%)$ & 11,7 & & \\
\hline
\end{tabular}

After 7 days in water, we observe the strengthening effect of micro basalt - which is expressed in an increase in the compression load already by $10-15 \%$ compared to the H-polymer that is aged in water. Experience has shown that micro basalt composites are in fact not afraid of exposure to water - unlike H-polymer. Bending strength drop (approximately 2 times) after filling is a tendency characteristic of almost all epoxy fillers. At the same time, we see a double growth of the modulus at bending (especially at $50 \mathrm{wt} \%$ ), which is very important from a practical point of view.

Filling $15 \%$ by weight increases adhesion by tearing almost 1.5 times, and $50 \%$ by weight - by $67 \%$. This can be explained by the high affinity of the basalt phase to the steel surface. The density of composites with small and medium fillings varies little. However, at 50 it increases significantly and especially noticeably at $80 \%$ by weight (Table 2).

Table 2: Adhesion, density and abrasion or fire resistance.

\begin{tabular}{|c|c|c|c|c|}
\hline & Adhesion, $\mathbf{k g f}$ & Density $\boldsymbol{\rho}, \mathbf{g} \backslash \mathbf{c m}^{\mathbf{2}}$ & ${\text { Abrasion resist., } \mathbf{~ m}^{\mathbf{1}}}^{\text {Fire resistance, sec }}$ \\
\hline $\mathrm{H}(0 \%)$ & 120 & $1,7(100 \%)$ & 0.105 & 2-Jan \\
\hline $15 \%$ & 170 & $1,6(94 \%)$ & 0.137 & $3-\mathrm{Feb}$ \\
\hline $50 \%$ & 200 & $2,1(124 \%)$ & 0.124 & $4-\mathrm{Mar}$ \\
\hline $80 \%$ & - & $3,7(218 \%)$ & 0.161 & 6-Apr \\
\hline
\end{tabular}

\section{Swelling in Corrosive Environments}

\section{Acetate-Ethyl Acetate Mixture}

From the graphs of swelling in acetone-ethyl acetate (Figures 5-9), the unfilled polymer in the first days swells very actively, and after 2 days it shows signs of physical destruction (decay into parts). As a result, swelling is replaced by inverse processes of mass loss - as can be seen from the same behavior on the curves of unfilled samples (the difference in the degree of swelling is due to the difference in the masses of the samples). Filling with $15 \mathrm{wt} \%$ basalt retains the similarity of the swelling curve to the curve for $\mathrm{H} 1$ and
H2 (unfilled), strongly distorting its appearance towards smoothing the processes of swelling and weight loss. The $15 \mathrm{wt} \%$ sample also destructs, although later - after 5 days. Filling with micro basalt contributes to reducing the rate and degree of swelling in $35 \%$ H2O2 (Figure 10) - the more active the higher the percentage of filling. Visually, they show signs of peroxide oxidation (whiten), but they show no significant degradation (as in acetone). As can be seen from the curves, in this case the filling of $15 \mathrm{wt} \%$ (insignificant) does not lead to drastic changes in the character of swelling - which indicates the preservation of the structure of the polymer.

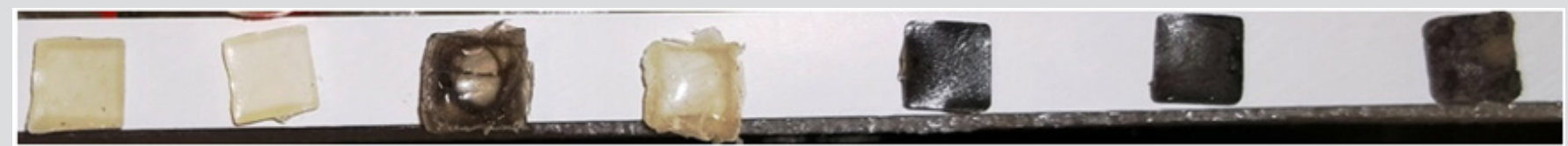

Figure 5: Neat samples. From left to right: H1, H2 (unfilleds); with basalt- \& glass-roving; with 15 wt $\%, 50$ wt $\%$ and 80 wt $\%$ of $\mathrm{BF}$.

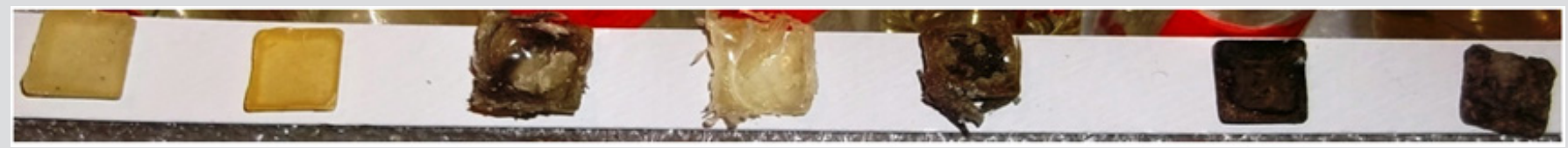

Figure 6: After 1 day of endurance in Acet:Etac.

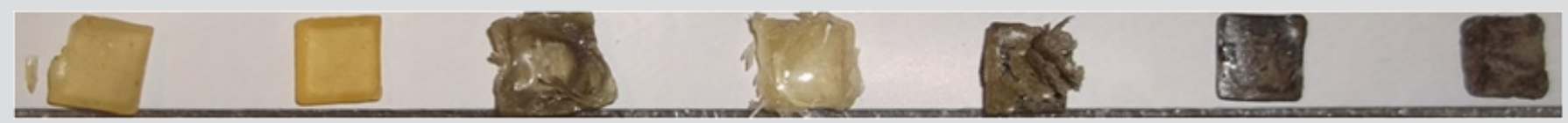

Figure 7: After 1 day of endurance in Acet:Etac. 


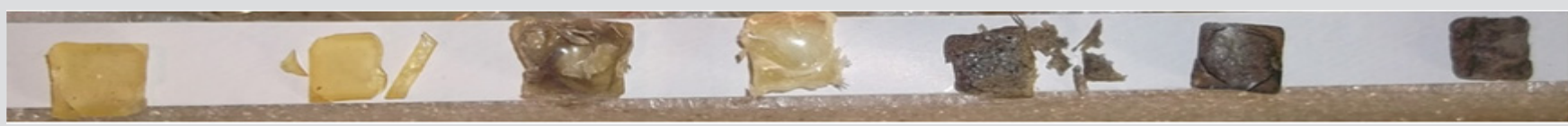

Figure 8: After 3 days of endurance in Acet:Etac.
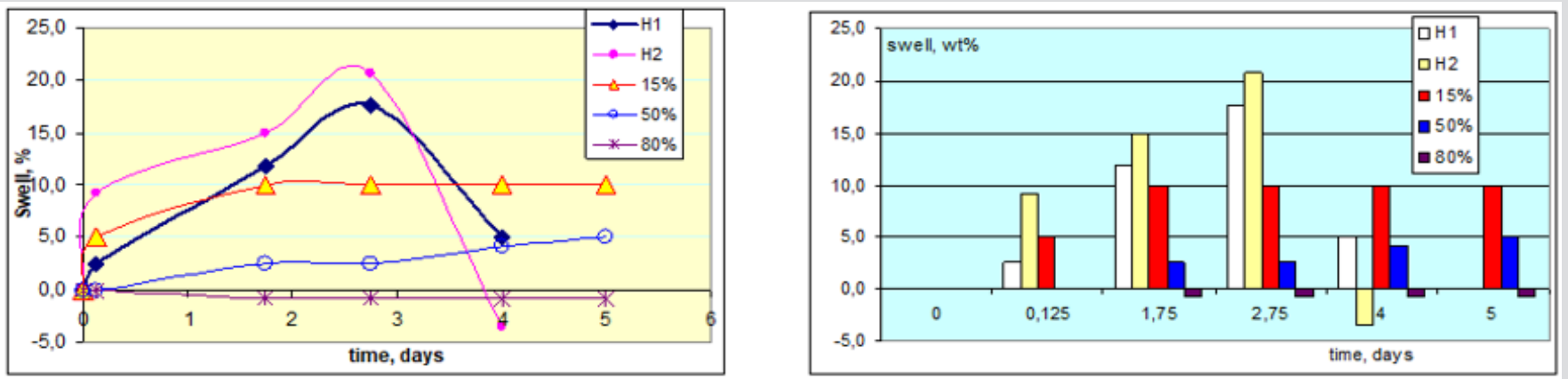

Figure 9: Curves \& histograms of swelling in Acet:Etac for composites - unfilled (H1 \& H2) and with 15-80 wt\% B.
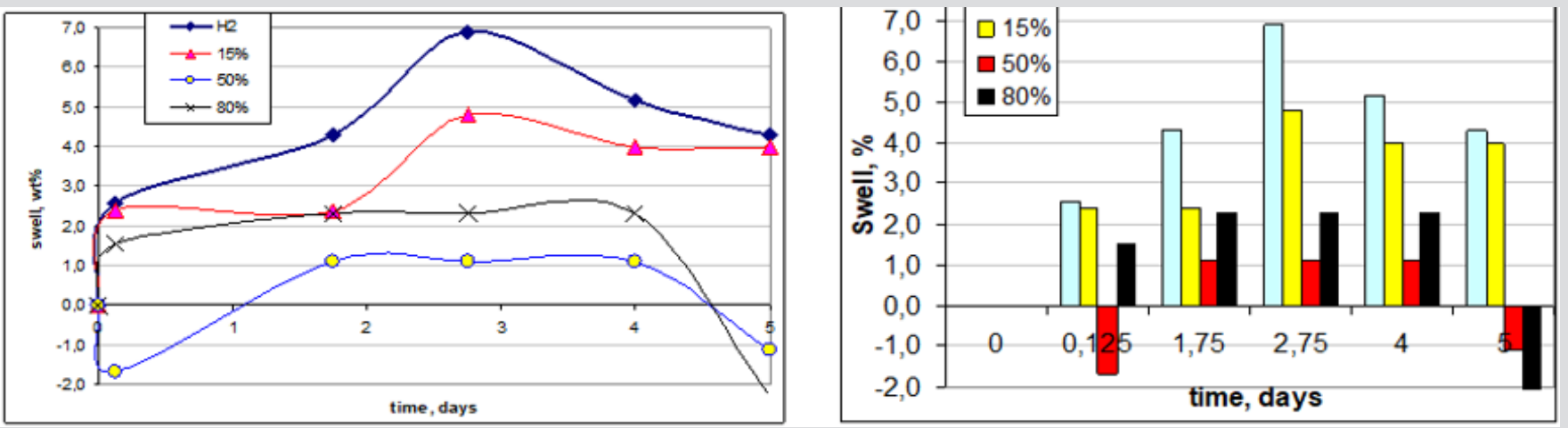

Figure 10: Curves \& histograms of swelling in 35\%- $\mathrm{M} \mathrm{H}_{2} \mathrm{O}_{2}$ for composites - unfilled (H1 \& H2) and with 15-80 wt $\%$ BF.

This cannot be said of composites with a high degree of filling - 50 and $80 w t \%$, the patterns of swelling of which are different than for unfilled and low-filled samples. This can be explained by compaction of the composite structure (with a decrease in the number of pores and permeable areas) and an increase in its resistance to aggressive effects due to an increase in the share of inorganic phases.

\section{Conclusion}

Introduction of basalt fiber into epoxy resin is possible in a very wide range of concentrations - up to $85 \mathrm{wt} \%$, with the formation of viscous well-formed black masses, cured in the usual way. Cured composites have increased fire resistance, which grows with increasing filling. But effect of filling on thermo-oxidative destruction was not observed. Filling gives some increase in compressive strength, which is especially clearly seen after the composites are kept in water (an increase of 10-15\%). The growth of the elastic modulus (by 15-25\%) is more noticeable - the higher the degree of filling is higher. With increasing filling, the density of composites increases (for 50-80 wt\%), abrasion resistance (by
24-60\%) and adhesion to steel (by 40-60\%). BasaltFibre increases resistance to oxidizing media (H202) and solvents (acetone-ethyl acetate) - especially in the region of $50-80 \mathrm{wt} \%$. According to their properties, these composites can be used as high-strength and resistant to aggressive actions substitutes for loaded structures. Including in biomedicine.

\section{References}

1. E Salernitano, C Migliaresi (2003) Composite Materials for Biomedical Applications: A Review// Journal of applied biomaterials \& biomechanics (JABB) 1(1): 3-18.

2. (2018) Master Bond EP42HT-2Med. Epoxy use in prosthetics and medical devices. TodaysMedical - 4 .

3. DL Starokadomsky (2008) Effect of the content of unmodified nanosilica with varied specific surface area on physicomechanical properties and swelling of epoxy composites. Russian Journal of Applied Chemistry 81(11): 1987-1991.

4. M Pavar, A Patnaik, R Nagar (2017) Investigation on mechanical and thermo-mechanical properties of granite powder filled treated jute fiber reinforced epoxy composite. Polymer Composites 38(4): 736-748.

5. Starokadomsky DL (2012) About Possibilities of Strengthening of Epoxypolymer Composites by Modificated Brick Powder. American Journal of Polymer Science 2(5): 109-114. 
6. Starokadomsky D (2018) Physical and mechanical properties and micro-nanostructure of epoxy composites filled with gypsum, chalk and cement. Composites and Nanostructures 10(1): 39-51.

7. MH Lapena, G Marinucci (2017) Mechanical Characterization of Basalt and Glass Fiber Epoxy Composite Tube. Mat Res 21(1).

8. G Wu, Z Dong, X Wang (2014) Prediction of Long-Term Performance and Durability of BasaltFibreRP Bars under the Combined Effect of Sustained Load and Corrosive Solutions. J Composites for Construction 19(3).

9. M Inman, E Thorhalsson, K Azrague (2017) A mechanical and environmental assessment and comparison of basalt fibre reinforced polymer (BFRP) rebar and steel rebar in concrete beams. Energy Procedia 111: 31-40.

10. MH Niaki, A Fereidoon, M Ahangari (2018) Mechanical properties of epoxy/basalt polymer concrete: Experimental and analytical study. Structural Concrete 19(2): 366-373.

\section{ISSN: 2574-1241}

DOI: 10.26717/BJSTR.2019.18.003092

Starokadomsky D. Biomed J Sci \& Tech Res

This work is licensed under Creative Commons Attribution 4.0 License

Submission Link: https://biomedres.us/submit-manuscript.php
11.D Matykiewicz, K Lewandowski, B Dudziec (2017) Evaluation of thermomechanical properties of epoxy-basalt fibre composites modified with zeolite and silsesquioxane. Composite Interfaces 24(5): 1-10.

12. M Bulut (2017) Mechanical characterization of Basalt/epoxy composite laminates containing graphene nanopellets. Composites Engineering 122: $71-78$

13. SV Ulegin, Yu A Kadykova, SE Artemenko, SA Demidova (2013) Basaltfilled epoxy composite material. Plasticheskie Massy 2: 31-33.

14. Xu, J Li, J Ding (2013) Chemical recycling of carbon fibre/epoxy composites in a mixed solution of peroxide hydrogen and $\mathrm{N}, \mathrm{N}$-dimethylformamide. Composites Sci Tech 82: 54-59.

15. H Shen, M Auad, C Huang, S Nutt (2009) Basalt fiber-epoxy laminates with functionalized multi-walled carbon nanotubes. Composites A 40(8): 1082-1089.

$\begin{array}{ll}\text { BIOMEDICAL } & \text { Assets of Publishing with us } \\ \text { RESEARCHES } & \text { - Global archiving of articles } \\ & \text { - Immediate, unrestricted online access } \\ \end{array}$

